\title{
Análise da Microestrutura e da Resistência ao Desgaste de Revestimento Duro Utilizado pela Indústria Sucroalcooleira
}

\author{
(Analysis of Microstructure and Wear Strength of Hardfacing used by the Sugar and Alcohol Industry)
}

\author{
Aldemi Coelho Lima ${ }^{1}$, Valtair Antonio Ferraresi ${ }^{2}$ \\ ${ }^{1}$ Centro Federal de Educação Tecnológica de Goiás, CEFET-GO, Goiânia, Goiás, Brasil acl@cefetgo.br \\ ${ }^{2}$ Universidade Federal de Uberlândia, UFU, Faculdade de Engenharia Mecânica, Uberlândia, MG, Brasil, valtairf@mecanica.ufu.br
}

\begin{abstract}
Resumo
O setor sucroalcooleiro tem apresentado um expressivo crescimento nos últimos anos no Brasil, entretanto, a manutenção das indústrias apresenta um elevado custo devido à perda de metal dos equipamentos por mecanismos de desgaste. O objetivo deste trabalho é avaliar a resistência ao desgaste abrasivo e a microestrutura de revestimentos duros depositados em camada única. Foram utilizados quatro tipos de consumiveis utilizados na indústria sucroalcooleira: um eletrodo revestido da liga $\mathrm{FeCrC}$ de 4,0 mm de diâmetro e três arames tubulares autoprotegidos de 1,6 mm de diâmetro, de ligas $\mathrm{FeCrC}, \mathrm{FeCrCNb}, \mathrm{FeCrCTiMo.} \mathrm{O} \mathrm{metal} \mathrm{de} \mathrm{base} \mathrm{utilizado} \mathrm{foi} \mathrm{um} \mathrm{aço} \mathrm{SAE}$ 1020. As soldagens com os arames tubulares foram efetuadas no modo de transferência por curto-circuito, com mesmos valores de corrente e tensão de soldagem. Para o ensaio de desgaste utilizou-se o abrasômetro Roda de Borracha, segundo a norma ASTM G6591. Os corpos de prova de desgaste foram retirados da região central das chapas de testes e da mesma região retirou-se dois conjuntos de amostras para análise microestrutural (microscopia ótica). Os resultados dos ensaios com a roda de borracha mostrou que a liga $\mathrm{FeCrCNb}$ apresenta maior resistência a desgaste, seguida do eletrodo revestido e com pior desempenho a liga FeCrCMoTi e a liga $\mathrm{FeCrC}$. A liga $\mathrm{FeCrC}$ (tanto para o eletrodo revestido como para o arame tubular) apresentou microestrutura formada por carbonetos primários $M_{7} C_{3}$ distribuidos em uma matriz de menor dureza; a liga contendo $\mathrm{Nb}$ apresentou microestrutura similar além da presença de carbonetos NbC; por sua vez, a liga com adição de Ti e Mo apresentou a presença de grandes carbonetos primários de titânio.
\end{abstract}

Palavras-chave: microestrutura, desgaste abrasivo, revestimento duro, arame tubular.

\begin{abstract}
The Brazilian sugar/alcohol sector presented expressive growth in recent years. However, maintenance cost is high due to metallic losses by wear. This paper studies the application of hardfacing by flux cored arc welding on the wear resistance and microstructure of single layer weld beads. Four types of consumable were used: three selfshielded flux cored wires of $1.6 \mathrm{~mm}$ diameter of alloys $\mathrm{FeCrC}, \mathrm{FeCrCNb}, \mathrm{FeCrCMoTi}$ and a covered electrode of $\mathrm{FeCrC}$ alloy of $4 \mathrm{~mm}$ diameter. The base metal was SAE 1020 steel. Test specimens were evaluated using Rubber Wheel Abrasion Test (ASTM G65). The selfshielded flux cored wires were welded in short-circuit transfer mode with the same current and voltage values. Wear evaluation was by mass loss and microstructure analysis by optic microscopy. The results of the trials with Rubber Wheel Test showed that the FeCrCNb alloy presented the largest wear resistance, followed by the covered electrode. The $\mathrm{FeCrC}+\mathrm{Ti}$ alloy and the $\mathrm{FeCrC}$ alloy presented the worst performance. The $\mathrm{FeCrC}$ alloy (for both covered electrode and tubular wire) presented microstructure formatted by primary $M_{7} C_{3}$ carbides distributed in a smaller hardness matrix; the alloy containing $\mathrm{Nb}$ presented a similar microstructure apart from its carbides that were mainly $\mathrm{NbC}$. The alloy with Ti and Mo addition presented large titanium primary carbides.
\end{abstract}

Keywords: microstructure, abrasive wear, hardfacing, tubular wire.

\section{Introdução}

O setor sucroalcooleiro vem apresentando grande expansão nos últimos anos, no Brasil, em função da estabilidade do mercado mundial do açúcar e do aumento de consumo do etanol no mercado interno e pelo aumento da meta de utilização de biocombustíveis nos EUA, União Européia e Japão. O País é, portanto, o maior produtor de açúcar do mundo e o segundo maior produtor de etanol, atrás apenas dos EUA, cuja produtividade, a partir do milho, é bastante inferior. Por sua vez, a perda de

(Recebido em 17/03/2009; Texto Final em 02/06/2009). material por mecanismos de desgaste representa um custo significativo para a operação de usinas de açúcar e destilarias de álcool, onde a deterioração das ferramentas é grande e a vida em serviço dos componentes é curta [1].

Verifica-se em usinas de açúcar e destilarias de álcool que os equipamentos que apresentam condições mais críticas do ponto de vista de desgaste abrasivo são: a mesa alimentadora, o nivelador, os roletes, as volandeiras, os mancais, o picador, o desfibrador e as moendas. Enquanto a maior parte dos equipamentos pode ser recuperada durante a entressafra (novembro a março, na região centro-sul), as facas picadoras e os martelos desfibradores precisam ser substituídos periodicamente, sendo os maiores responsáveis pelo curto ciclo de paradas programadas para 
sua substituição [1]. Essas ferramentas são recuperadas por soldagem pela aplicação de revestimentos duros, utilizando-se diferentes processos, técnicas e consumíveis para a reposição do metal desgastado em serviço. Tradicionalmente, a aplicação de revestimentos duros pelo setor industrial tem sido feita manualmente com o processo Eletrodo Revestido ou de forma automática com o processo Arco Submerso, quando a geometria ou dimensões da peça se adequam a essa aplicação. Devido à sua maior produtividade em relação ao primeiro, aliada à maior versatilidade quando comparado ao segundo, o processo Arame Tubular tem se tornado uma alternativa importante, contando com uma grande variedade de consumíveis para diferentes aplicações de revestimentos duros [2].

A aplicação de revestimentos com o objetivo de reduzir o desgaste e, consequentemente os custos, busca o incremento da vida em serviço dos componentes e na redução das paradas para manutenção. Uma correta seleção do material depositado permite, dentre outras coisas, transformarem elementos descartáveis por desgaste em bens de capital recuperável, aumentar a resistência e prover as superfícies susceptíveis ao desgaste de características e propriedades desejadas e, em geral, aumentar a eficiência do processo em que tomam parte os elementos reconstruídos e/ou protegidos.

Existem muitos trabalhos disponíveis na literatura, abordando o efeito da microestrutura na resistência ao desgaste. A maioria dos autores é unânime em afirmar que a microestrutura dos revestimentos tem papel preponderante no seu desempenho em termos de resistência ao desgaste. Fiore et al. [3] afirmam que as ligas de ferro fundido branco ao alto cromo possuem inúmeras vantagens em aplicações de desgaste abrasivo, pois suas composições podem ser ajustadas para que elas contenham quantidades moderadas de cromo. Dessa forma, produz na solidificação, microestrutura rica em carbonetos de cromo massivos e uma matriz austenítica de temperabilidade suficiente para ser transformada em martensita com tratamentos térmicos relativamente simples. Os carbonetos afetam as propriedades mecânicas dos materiais por sua presença dentro dos grãos e em seus contornos. Dependendo da composição da liga e do tratamento térmico recebido podem se apresentar distintos tipos de carbonetos, como $\mathrm{MC}, \mathrm{M}_{6} \mathrm{C}, \mathrm{M}_{7} \mathrm{C}_{3}, \mathrm{M}_{23} \mathrm{C}_{6}$ e $\mathrm{Cr}_{2} \mathrm{C}_{3}$, onde $\mathrm{M}$ representa um ou mais tipos de átomos metálicos.

De acordo com Hernandez [4], as ligas do sistema Fe-C$\mathrm{Cr}-\mathrm{Nb}$ apresentam essencialmente o mesmo tipo de contraste de microestrutura das ligas contendo apenas $\mathrm{Fe}-\mathrm{C}-\mathrm{Cr}$, formando-se dendritas de austenita ou carbonetos $\mathrm{M}_{7} \mathrm{C}_{3}$ massivos, além da presença de carbonetos $\mathrm{NbC}$, na forma primária, e/ou em frações mais finas, oriundas de reações mais complexas do sistema quaternário. Ensaios abrasivos em ligas fundidas desse sistema indicaram que é possível obter um menor desgaste de ligas austeníticas fundidas contendo $(\mathrm{Fe}, \mathrm{Cr})_{7} \mathrm{C}_{3}$, pela substituição parcial desse carboneto de cromo por carbonetos $\mathrm{NbC}$, para certas porcentagens de fases e características microestruturais.

Para Martins Filho [5], a maior resistência ao desgaste abrasivo é obtida pelos ensaios com menor aporte térmico, isentos de trincas e que proporciona microestrutura com alto teor de austenita. Já no estudo de Hernandez [4], a microestrutura de maior resistência à abrasão foi o carboneto primário numa matriz eutética de carbonetos mais austenita obtidas em revestimento com maior teor de $\mathrm{Cr}$ e C. Isso ocorreria pelo aumento da fração volumétrica dos carbonetos e pela diminuição da largura das dendritas de austenita, as quais ficaram menos expostas à ação das partículas abrasivas.

Segundo Paranhos et al. [6], o aumento dos teores de C e Cr reduzem a possibilidade de formação de austenita primária e o aumento da formação de microestrutura composta de carboneto primário do tipo $\mathrm{M}_{7} \mathrm{C}_{3}$ e eutético austenita-carbeto $\left(\mathrm{M}_{7} \mathrm{C}_{3}\right)$, a microestrutura que apresenta maior resistência à abrasão de baixa tensão.

Os revestimentos duros ricos em cromo com carbonetos primários em matriz eutética apresentam melhor resistência ao desgaste abrasivo que aqueles compostos por constituintes eutéticos e austenita [7].

Segundo Buchely et al. [8], Os carbonetos de cromo do tipo $\mathrm{M}_{7} \mathrm{C}_{3}(1800 \mathrm{HV})$ têm um importante papel na resistência ao desgaste abrasivo devido à sua ação como barreira ao corte e ao sulcamento provocado pelas partículas abrasivas. Em seu estudo com desgaste abrasivo em ensaio Roda de Borracha, verificou a superioridade dos carbonetos complexos na terceira camada, seguido do revestimento rico em cromo (segunda camada). Nos revestimentos em primeira camada, o melhor resultado foi da liga rica em $\mathrm{W}$, seguido da liga rica em $\mathrm{Cr}$ e por fim da liga rica em carbonetos complexos $\left(\mathrm{NbC}, \mathrm{M}_{7} \mathrm{C}_{3}, \mathrm{Mo}_{2} \mathrm{C}\right)$. As primeiras camadas apresentaram resistência ao desgaste inferior às camadas posteriores.

O objetivo deste trabalho é, portanto, avaliar a resistência ao desgaste abrasivo e a microestrutura de revestimentos duros depositados em camada única com três arames tubulares autoprotegidos e um com o processo Eletrodo Revestido (ER1), utilizados na indústria sucroalcooleira, principalmente nas facas picadoras e desfibradores de cana-de-açucar. O eletrodo revestido foi avaliado para servir de referência em uma análise comparativa do desempenho dos arames tubulares, apesar da utilização de condição de soldagem diferente da usada pelos arames tubulares.

\section{Materiais e Métodos}

Foi utilizada uma fonte de soldagem eletrônica multiprocesso ajustada para soldar no modo de tensão constante, processo arame tubular e no modo de corrente constante para o processo eletrodo revestido. As soldas foram efetuadas com quatro consumíveis de liga $\mathrm{FeCrC}$, sendo um com eletrodo revestido de diâmetro de 4,0 $\mathrm{mm}$ e três arames tubulares autoprotegidos de $1,6 \mathrm{~mm}$ de diâmetro; os arames tubulares da liga $\mathrm{FeCrC}$ diferem entre si pelos teores de ferro, cromo, carbono, silício e manganês, além da adição de $\mathrm{Nb}$ em uma liga e da adição de Ti e Mo em outra. Doravante os consumíveis serão denominados, respectivamente, de $\mathrm{FeCrC},+\mathrm{Nb},+\mathrm{Ti}$ e ER1. A Tabela 1 apresenta a faixa de dureza a ser obtida pelo metal de solda em primeira camada, bem como, a composição típica dos arames, cujos dados foram obtidos do fabricante.

A soldagem foi efetuada em camada única, com cordões de $150 \mathrm{~mm}$ de comprimento (cinco cordões para o revestimento) em chapas de aço SAE 1020 de 12,7 x 50,8 x $200 \mathrm{~mm}$. Com cada 
tipo de eletrodo foram soldadas cinco chapas e, da região central das mesmas foram extraídos os corpos de prova (CPs) para a avaliação de desgaste. A Tabela 2 apresenta os parâmetros de soldagem utilizados. Para o processo arame tubular a indutância de subida e descida, a velocidade de alimentação do arame $\left(\mathrm{V}_{\text {alim }}\right)$, a velocidade de soldagem $\left(\mathrm{V}_{\text {sold }}\right)$ e a tensão de referência $\left(\mathrm{U}_{\mathrm{r}}\right)$ foram mantidas constantes, em condições que proporcionaram a transferência metálica no modo de curto-circuito.

As condições de soldagem foram obtidas de trabalhos anteriores de Lima e Ferraresi [9], com os respectivos arames.
A distância bico de contato-peça (DBCP) foi variada com vistas à obtenção de mesma corrente de soldagem para taxa de fusão constante (mesma $\mathrm{V}_{\text {alim }}$ ), já que arames tem composição química diferentes. Esse procedimento foi importante para se avaliar a resistência ao desgaste dos depósitos de solda quando realizados com mesma corrente de soldagem e mesmo volume de metal depositado por comprimento de solda $\left(\mathrm{V}_{\text {alim }}\right.$ e $\mathrm{V}_{\text {sold }}$ constantes). Para o processo eletrodo revestido as condições de soldagem são as mesmas utilizadas na indústria e indicada pelo fabricante do eletrodo.

Tabela 1. Dados dos consumíveis (arames tubulares e eletrodo revestido).

\begin{tabular}{|c|c|c|c|c|c|c|c|c|c|c|}
\hline \multirow{2}{*}{$\begin{array}{c}\text { Tipo de } \\
\text { eletrodo }\end{array}$} & \multirow{2}{*}{ Dureza HRc } & \multicolumn{10}{|c|}{ Composição química (\%) } \\
\cline { 3 - 12 } & & $\mathbf{C}$ & $\mathbf{C r}$ & $\mathbf{M n}$ & $\mathbf{S i}$ & $\mathbf{S}$ & $\mathbf{P}$ & $\mathbf{N b}$ & $\mathbf{M o}$ & $\mathbf{T i}$ \\
\hline FeCrC & $59-61$ & 4,110 & 23,100 & 0,520 & 0,200 & 0,000 & 0,000 & - & - & - \\
\hline $\mathrm{FeCrC}+\mathbf{N b}$ & $57-64$ & 4,500 & 22,000 & 0,500 & 0,600 & 0,002 & 0,001 & 6,500 & - & - \\
\hline $\mathrm{FeCrC}+\mathbf{T i}$ & $52-64$ & 1,800 & 7,500 & 0,840 & 0,500 & 0,018 & 0,027 & - & 1,500 & 5,260 \\
\hline ER1 & $58-63$ & 5,100 & 44,00 & 0,750 & 1,250 & 0,025 & 0,035 & - & - & - \\
\hline
\end{tabular}

Tabela 2. Parâmetros de soldagem para confecção dos corpos de prova para ensaio de desgaste.

\begin{tabular}{|c|c|c|c|c|c|c|c|}
\hline $\begin{array}{l}\text { Tipo de } \\
\text { Arame }\end{array}$ & $\begin{array}{r}\text { Diâm } \\
(\mathrm{mm})\end{array}$ & $\underset{(\mathrm{m} / \mathrm{min})}{\mathbf{V}_{\text {alim }}}$ & $\begin{array}{c}\mathbf{V}_{\text {sold }} \\
(\mathrm{cm} / \mathrm{min})\end{array}$ & $\begin{array}{l}\mathbf{U}_{\mathrm{r}} \\
(\mathrm{V})\end{array}$ & $\begin{array}{c}\mathbf{P} \\
(\mathrm{mm})\end{array}$ & $\begin{array}{c}\text { DBCP } \\
(\mathrm{mm})\end{array}$ & $\begin{array}{l}\mathbf{I}_{\text {des }} \\
(A)\end{array}$ \\
\hline $\mathrm{FeCrC}$ & \multirow{3}{*}{1,6} & \multirow{3}{*}{10} & \multirow{3}{*}{50} & \multirow{3}{*}{28} & 6 & 35 & 270 \\
\hline $\mathrm{FeCrC}+\mathbf{N b}$ & & & & & 6 & 30 & 270 \\
\hline $\mathrm{FeCrC}+\mathbf{T i}$ & & & & & 7 & 32 & 270 \\
\hline ER1 & 4 & - & 15 & 40 & 6 & - & 170 \\
\hline
\end{tabular}

Onde: $I_{\text {des }}=$ corrente desejada; $P=$ passo de soldagem, ou a distância entre centros de cordões adjacentes.

Os corpos de prova foram retirados da região central das chapas de testes por corte em cortadora metalográfica. O revestimento foi retificado na superfície até a sua uniformização, seguido da usinagem (fresamento e retificação) da face oposta ao revestimento e das laterais, até a obtenção das dimensões padronizadas. A Figura 1 apresenta a vista superior de uma chapa de teste revestida, bem como a seção transversal ilustrando a região de retirada dos corpos de prova de desgaste.

Foram extraídas amostras das chapas soldadas para se efetuar a avaliação microestrutural dos revestimentos (Figura 1). As amostras foram embutidas, lixadas com lixa de grana 180 a 1000 e polidas com pasta de diamante de $3 \mu \mathrm{m}, 1 \mu \mathrm{m}$ e $0,25 \mu \mathrm{m}$.
Posteriormente foram atacadas com reagente Nital $2 \%$ por $10 \mathrm{~s}$ para revelar os microconstituintes e levadas ao microscópio ótico para a observação da microestrutura. Para a revelação de carbonetos foram utilizados os mesmos procedimentos de preparação e o ataque químico com o reagente Murakami a $60^{\circ}$ por 10 segundos. Foram realizados também medidas de microdureza.

Os ensaios de desgaste foram realizados utilizando-se um abrasômetro Roda de Borracha, ilustrado pela Figura 2, o qual é recomendado para simulação de desgaste abrasivo de baixa tensão, seguindo as orientações da norma ASTM G65-91 [10], dentre as quais se destacam: as dimensões das amostras foram

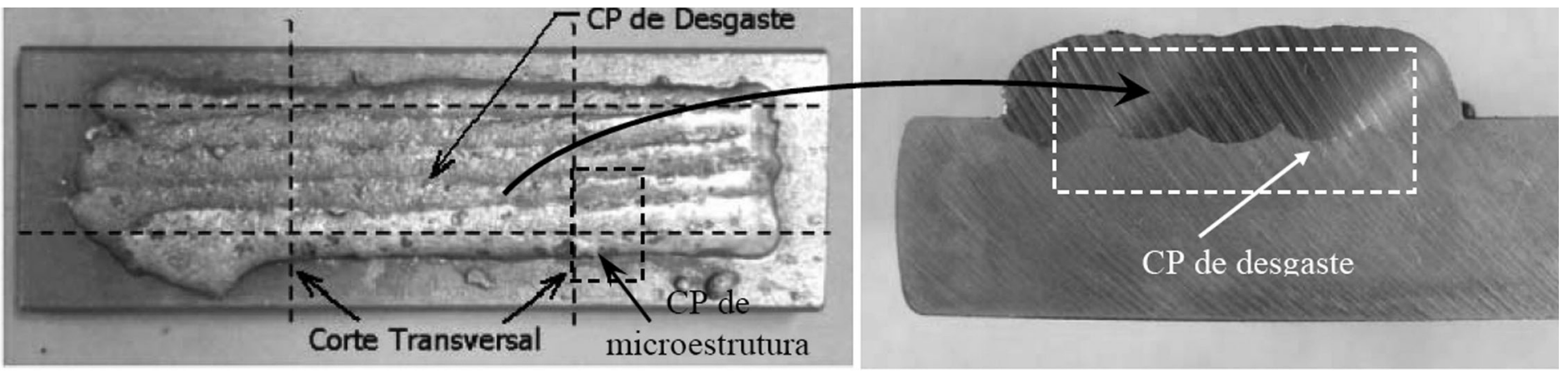

Figura 1. Chapa de testes e região de extração dos corpos de prova para avaliação de desgaste e microestrutura. 
de $10 \times 25$ x $55 \mathrm{~mm}$; disco de $12,7 \times 228 \mathrm{~mm}$; anel de borracha com dureza de 60 Shore A; a areia Normal Brasileira $\mathrm{n}^{\circ} 100$ $(0,15 \mathrm{~mm})$; rotação do disco de $200 \mathrm{RPM}$; tempo de ensaio de $10 \mathrm{~min}$ (ensaio tipo A); força nominal de $130 \mathrm{~N}$; a pesagem das amostras, antes e após a soldagem foi efetuada em balança eletrônica com resolução de $10^{-5} \mathrm{~g}$. Todas as amostras foram prédesgastadas por 5 minutos até atingir o regime de desgaste. Para cada tipo de arame foram realizados cinco ensaios. O desgaste foi obtido em função da perda de peso dos corpos de prova pela comparação entre o peso antes e após o ensaio. Antes da pesagem, as amostras foram cuidadosamente limpas imersas em acetona, em equipamento de limpeza por ultra-som e, em seguida, secas com ar quente. A resistência ao desgaste foi obtida pela relação inversa do desgaste dividido pela distância percorrida durante o ensaio.

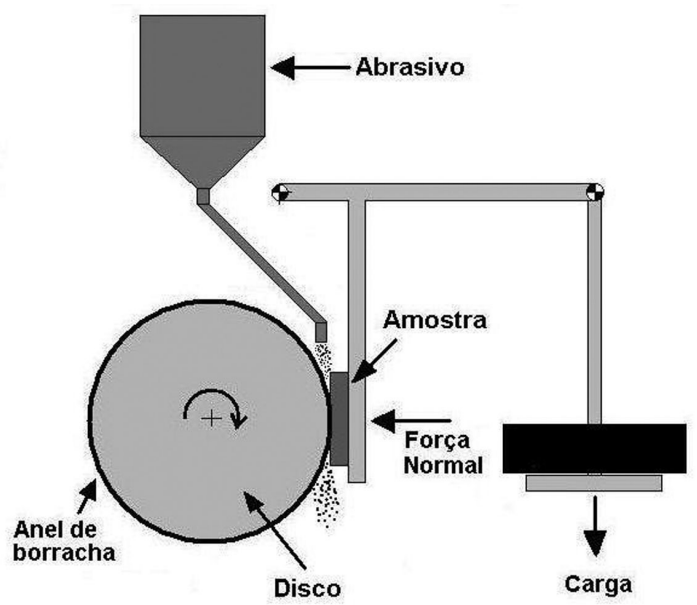

Figura 2. Esquema do abrasômetro Roda de Borracha.

Foram realizados ensaios de dureza e microdureza. Para a medição de dureza Rockell $\mathrm{C}$, foi utilizado um durômetro Wolpert Testor HT1, com carga de $150 \mathrm{~kg}$. Já para a medição da microdureza das fases utilizou-se de um microdurômetro Mitutoyo HM - Hardness Testing Machine, com carga de 10 gramas. Foi determinada também a porcentagem volumétrica de carbonetos totais (PVCt), medido através do software "Image Tools". Para a obtenção das imagens os corpos de prova foram atacados com o reagente Murakami $\left(60^{\circ} \mathrm{C}\right)$.

Para complementar o estudo abrasométrico dos CPs de desgaste foi feita a caracterização da topografia de superfície da trilha de desgaste via interferometria a laser, utilizando o equipamento NEOPHOT 21. Para isso foi selecionada uma área de $3 \times 3 \mathrm{~mm}$ em região representativa da superfície de interesse, na qual foi feita a varredura com taxa de aquisição de 1000 pontos $/ \mathrm{mm}$ em " $X$ " (eixo transversal à trilha de desgaste) e 50 pontos/mm em "Y" (eixo longitudinal à trilha de desgaste). Os parâmetros de rugosidade superficial $(S a$ e $S q$ ) foram obtidos pelo software digital "Surf Montains Map Universal 3.0".

\section{Resultados e Discussões}

\subsection{Resistência ao Desgaste}

A Tabela 3 apresenta os resultados da avaliação em termos de resistência ao desgaste para os cincos corpos de prova construídos com cada consumível utilizado. Para uma melhor visualização dos resultados a Figura 3 ilustra a resistência ao desgaste médio por consumível. Observa-se que dentre os arames tubulares, o melhor resultado foi obtido pelo arame $+\mathrm{Nb}$, seguido do $+\mathrm{Ti}$ e, com o pior resultado, o arame $\mathrm{FeCrC}$, apesar de os dois últimos serem estatisticamente iguais em teste de hipótese. O eletrodo revestido ER1 proporcionou o segundo melhor resultado geral, dentre todos os consumíveis, com média de perda de massa $26 \%$ superior ao arame $+\mathrm{Nb}$, mas pela sobreposição do desvio padrão, com resultado estatisticamente similar a este.

A superioridade do revestimento $+\mathrm{Nb}$ sobre o $\mathrm{FeCrC}$ de certa forma é discordante dos resultados de Buchely et al. [8] que avaliou revestimentos depositado com o processo eletrodo revestido, segundo o qual, nos revestimentos em primeira camada, como neste trabalho, a liga rica em $\mathrm{Cr}$ apresentou maior resistência ao desgaste abrasivo de baixa tensão que a liga rica em carbonetos complexos, como $\mathrm{NbC}, \mathrm{M}_{7} \mathrm{C}_{3}$ e $\mathrm{Mo}_{2} \mathrm{C}$. Os autores concluíram que os revestimentos formados por carbonetos complexos (liga C-Cr-W-Nb-Mo-V), de composição química diferente dos consumíveis utilizados neste trabalho, são inferiores aos ricos em cromo no ensaio de desgaste abrasivo de baixa tensão (Roda de Borracha), tanto na primeira quanto na segunda camada.

Tabela 3. Dados de desgaste por consumível.

\begin{tabular}{|c|c|c|c|c|c|}
\hline Consumível & $\begin{array}{l}\text { Desg } \\
(\mathrm{mg})\end{array}$ & $\begin{array}{c}\text { Desg }_{m} \\
(\mathrm{mg})\end{array}$ & $\begin{array}{c}\text { DP } \\
\text { Desg }\end{array}$ & $\begin{array}{l}\text { Rdesg }_{\mathrm{m}} \\
\left(\mathrm{mg} \cdot \mathrm{m}^{-1}\right)^{-1}\end{array}$ & $\begin{array}{c}\text { DP } \\
\text { Rdesg }\end{array}$ \\
\hline \multirow{5}{*}{$\mathrm{FeCrC}$} & 230,3 & \multirow{5}{*}{186,7} & \multirow{5}{*}{50,0} & \multirow{5}{*}{7,69} & \multirow{5}{*}{2,59} \\
\hline & 237,2 & & & & \\
\hline & 164,5 & & & & \\
\hline & 115,5 & & & & \\
\hline & 185,9 & & & & \\
\hline \multirow{5}{*}{$\begin{array}{c}\mathrm{FeCrC}+ \\
\mathrm{Nb}\end{array}$} & 50,6 & \multirow{5}{*}{42,2} & \multirow{5}{*}{12,6} & \multirow{5}{*}{34,48} & \multirow{5}{*}{13,52} \\
\hline & 24,1 & & & & \\
\hline & 37,3 & & & & \\
\hline & 42,2 & & & & \\
\hline & 56,7 & & & & \\
\hline \multirow{5}{*}{$\mathrm{FeCrC}+\mathrm{Ti}$} & 133,0 & \multirow{5}{*}{129,5} & \multirow{5}{*}{14,2} & \multirow{5}{*}{11,09} & \multirow{5}{*}{1,35} \\
\hline & 127,0 & & & & \\
\hline & 136,3 & & & & \\
\hline & 144,5 & & & & \\
\hline & 106,8 & & & & \\
\hline \multirow{5}{*}{ ER1 } & 60,3 & \multirow{5}{*}{53,2} & \multirow{5}{*}{14,7} & \multirow{5}{*}{27,03} & \multirow{5}{*}{7,43} \\
\hline & 47,3 & & & & \\
\hline & 75,1 & & & & \\
\hline & 37,3 & & & & \\
\hline & 46,0 & & & & \\
\hline
\end{tabular}

Nota: Desg = Desgaste por CP (diferença entre a pesagem inicial e final do corpo de prova); Desg ${ }_{m}=$ Desgaste médio por consumivel; Rdesg $_{m}=$ resistência ao desgaste média por consumível; $D P=$ Desvio Padrão. 


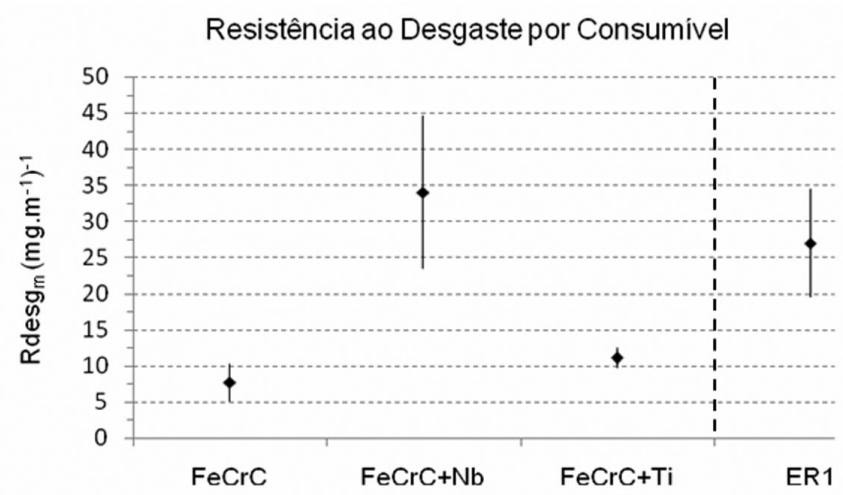

Figura 3. Análise comparativa de resistência ao desgaste por consumível.

Para efeitos de comparação com os resultados de Buchely et al. [8], observa-se que a resistência ao desgaste dos seus revestimentos variou de 11,2 a $32,3\left(\mathrm{mg} \cdot \mathrm{m}^{-1}\right)^{-1}$, sendo que em uma camada variou de 11,2 a $24,2\left(\mathrm{mg} \cdot \mathrm{m}^{-1}\right)^{-1}$. Neste trabalho, a resistência ao desgaste obtida por revestimento em camada única, variou de 7,69 a 34,48 (mg.m $\left.\mathrm{m}^{-1}\right)^{-1}$.

Uma comparação entre o trabalho de Buchely et al [8] e o revestimento depositado com o eletrodo revestido deste trabalho se faz necessário, apesar de as condições de soldagem, bem como, os eletrodos não serem os mesmos. Enquanto o eletrodo de liga Fe-35Cr-4,3C de Buchely et al [8] apresentou resistência ao desgaste na primeira camada de $14,7\left(\mathrm{mg} \cdot \mathrm{m}^{-1}\right)^{-1}$, o eletrodo ER1 (Fe-44Cr- 5,1C) deste trabalho apresentou resistência média de 27,03 (mg.m $\left.{ }^{-1}\right)^{-1}$, bem superior, indicando a importância do maior teor de cromo e carbono para aumentar a resistência ao desgaste abrasivo de baixa tensão.

As comparações feitas anteriormente mostram que apesar de serem consumíveis diferentes e soldados com condições distintas, resguardadas as devidas proporções, os resultados apresentados neste trabalho estão em acordo com a literatura.
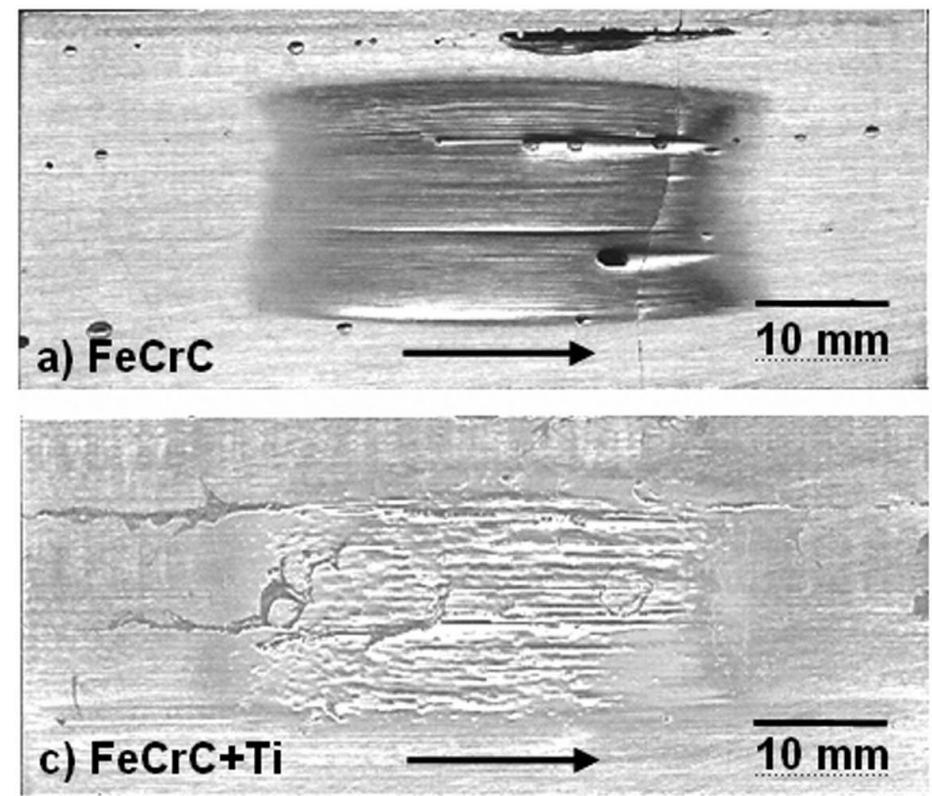

A Figura 4 ilustra as superfícies de desgaste, em tamanho natural, dos corpos de prova ensaiados, permitindo observar diferentes comportamentos por consumível. A seta na figura indica o sentido de entrada das partículas abrasivas durante o ensaio. Observa-se que o arame $\mathrm{FeCrC}$ e o $+\mathrm{Nb}$ proporcionaram revestimentos com trincas perpendiculares ao cordão e que o revestimento $+\mathrm{Ti}$ não apresentou trincas visíveis, enquanto o revestimento obtido com o eletrodo ER1 apresentou trincas sem uma direção preferencial. $\mathrm{O}$ arame $\mathrm{FeCrC}$ e o eletrodo ER1 apresentaram porosidades dispersas ao longo do revestimento, as quais podem ter contribuído para o desgaste, principalmente na região de saída do abrasivo. Visualmente observa-se maior uniformidade do desgaste do revestimento $+\mathrm{Nb}$, o qual apresentou superfície de desgaste com riscamento mais fino, enquanto os CPs revestidos com o $+\mathrm{Ti}$ apresentaram desgaste seletivo (regiões marcantes com diferentes resistências ao desgaste).

As superfícies de desgaste foram observadas em microscópio ótico com aumento de 50 vezes para uma análise mais detalhada dessa região, conforme é apresentado na Figura 5. Observa-se na figura a predominância de microcorte para os revestimentos com todos os consumíveis. No arame FeCrC e no ER1 os sulcos provocados pela penetração das partículas abrasivas foram mais profundos. A superfície do revestimento $+\mathrm{Ti}$, diferentemente dos demais consumíveis apresentou uma combinação de fases com diferente comportamento de resistência ao desgaste, onde a presença de regiões mais susceptíveis a ação das partículas abrasivas levaram à formação de crateras, sendo possível observarem os riscos tanto nos picos quanto nos vales.

A Figura 6 apresenta, a título de exemplo, os perfis gerados por interferometria a laser, da superfície de desgaste de um exemplar das amostras do revestimento obtido com cada um dos consumíveis utilizados, permitindo reforçar a diferença observada visualmente entre as superfícies dos mesmos. De modo a quantificar essas diferenças superficiais, foram calculados os valores de $S a$ (rugosidade superficial média), $S q$

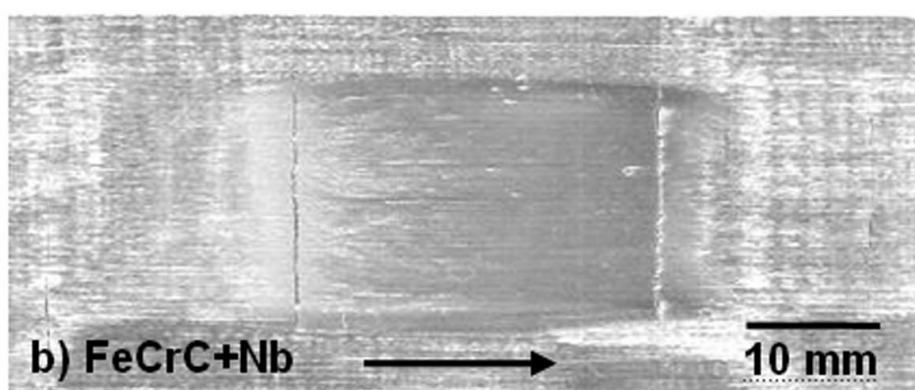

b) $\mathrm{FeCrC}+\mathrm{Nb}$

$10 \mathrm{~mm}$

d) ER1



Figura 4. Trilha de desgaste dos CPs para cada consumível. 



Figura 5. Imagens da trilha de desgaste por microscopia ótica.

(rugosidade superficial quadrática média), Ssk (coeficiente de simetria superficial - Skewness) e $S k u$ (coeficiente de achatamento superficial - Kurtosis), a partir dos perfis 3D obtidos para cada amostra, cujos valores são apresentados ao lado da respectiva figura.

Observa-se grande diferença entre os valores de $S a$ e $S q$ das amostras, cujos valores foram inferiores para o arame $+\mathrm{Nb}(8,85$ $\mu \mathrm{m}$ e $10,85 \mu \mathrm{m})$, intermediários para o arame $\operatorname{FeCrC}(37,60 \mu \mathrm{m}$ e 43,70 $\mu \mathrm{m})$ e $+\mathrm{Ti}(37,10 \mu \mathrm{m}$ e $43,80 \mu \mathrm{m})$, com valores muito próximos, e superiores para o eletrodo ER1 $(58,60 \mu \mathrm{m}$ e 68,30 $\mu \mathrm{m})$.

Segundo Carceller [11], os materiais com menor resistência ao desgaste abrasivo apresentam maior rugosidade superficial e esta tende a aumentar à medida que progride o desgaste. Concordando com esta afirmação, o arame $+\mathrm{Nb}$ de maior resistência ao desgaste foi o que apresentou menor rugosidade superficial, mas essa relação não se verificou com todos os materiais porque o ER1, de maior Rdesg que o $\mathrm{FeCrC}$ e o + Ti, como pôde ser observado na Figura 3, apresentou rugosidade superficial maior que estes. Zum Ghar [12] afirma que a diferença na rugosidade de amostras submetidas às mesmas condições de ensaios de desgaste é devido a diferentes microestruturas das amostras de cada consumível.

Diferentemente do perfil da superfície desgastada dos consumíveis $\mathrm{FeCrC}$, $+\mathrm{Nb}$ e ER1 que apresentaram sulcos no sentido de deslizamento do abrasivo, no caso do arame $+\mathrm{Ti}$ o desgaste provocou o surgimento de picos e vales aleatoriamente distribuídos na superfície, o que seria provocado pela existência de fases duras distribuídas em matriz menos resistente ao desgaste.

O coeficiente de simetria superficial ( $S s k)$ apresentou valores variando de -1,45 a 1,25. Quando Ssk é negativo, temse maior concentração de material abaixo do plano médio e quando é positivo, acima. De outra forma, o maior afastamento em relação ao zero significa a maior predominância de picos e vales, segundo Zum Ghar [12]. As trilhas de desgaste dos 

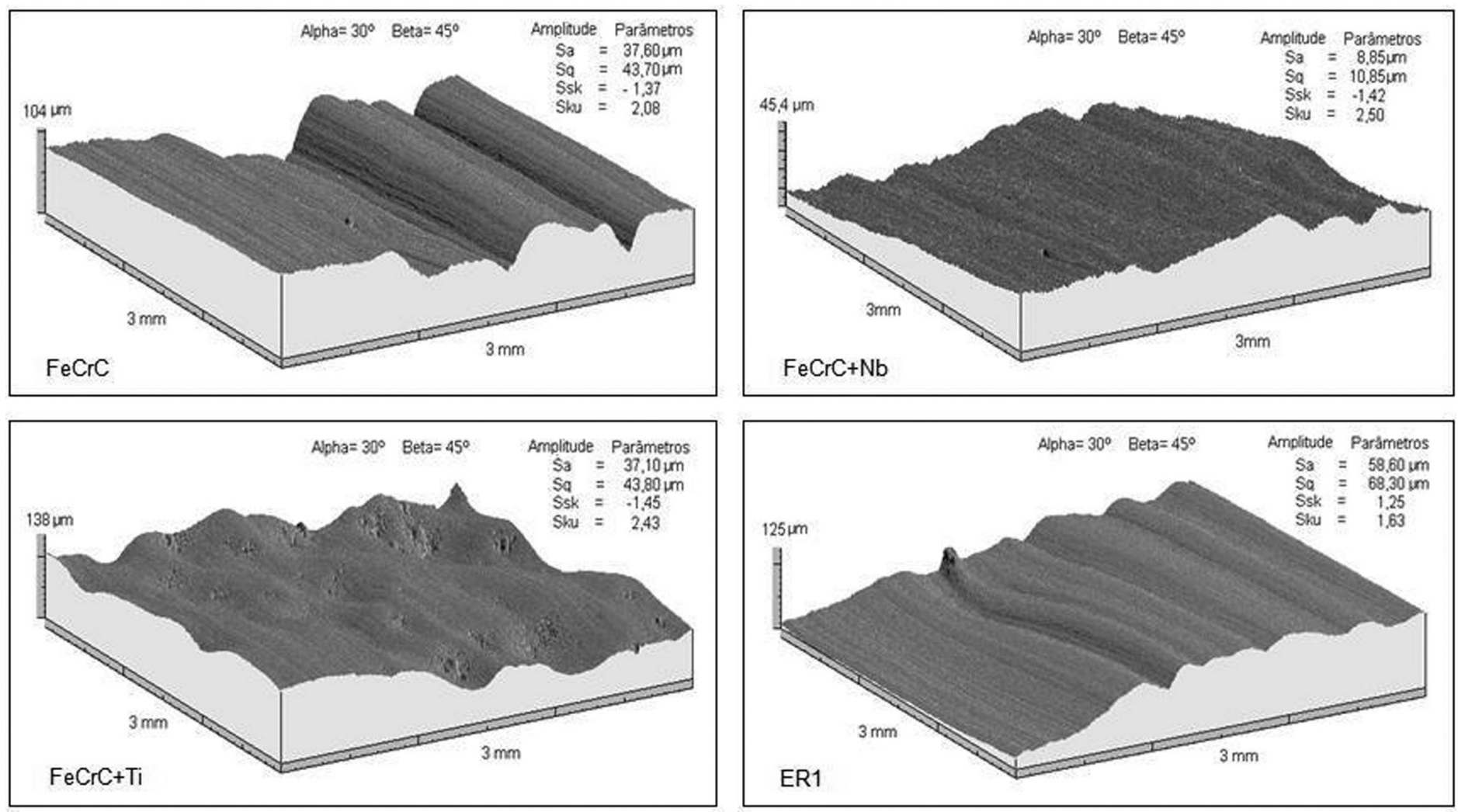

Figura 6. Perfil da trilha de desgaste por interferometria a laser para os quatro revestimentos.

revestimentos com arames tubulares apresentaram valores negativos, indicando a presença de mais material abaixo do plano médio, ou seja, picos maiores e vales mais estreitos. Além disso, apesar de perfil distinto da trilha de desgaste, os valores foram próximos, sendo que o $+\mathrm{Ti}$, com o maior afastamento em relação ao zero $(S s k=-1,45)$ apresentou maior predominância de picos e vales que os demais. Por sua vez, o eletrodo ER1 $(S s k=1,25)$ teve menor predominância de picos e vales e maior concentração de material acima do plano médio.

O coeficiente de achatamento $(S k u)$ teve variação de 1,63 a 2,50, caracterizando-se por uma distribuição de alturas não Gaussiana (valor diferente de 3). O valor 3, segundo Mummery [13], corresponde ao valor de kurtosis da distribuição das alturas de uma superfície para uma distribuição normal. O menor valor de $S k u$ ocorreu para o eletrodo ER1, seguido do arame $\mathrm{FeCrC}$, do + Ti e com o maior valor, o $+\mathrm{Nb}$.

\subsection{Microestrutura dos Revestimentos}

A Figura 7 ilustra a microestrutura obtida com o arame $\mathrm{FeCrC}$ por microscopia ótica após ataque com Nital $2 \%$. Observa-se que próximo à interface com o metal de base (Figura 7a) o revestimento $\mathrm{FeCrC}$ apresentou uma microestrutura com crescimento dendrítico (dureza média de $393 \mathrm{HV}_{0,01}$ ). No interior do revestimento (Figura $7 \mathrm{~b}$ ) nas regiões mais próximas à superfície do cordão de solda se observam carbonetos primários $\left(\mathrm{M}_{7} \mathrm{C}_{3}\right.$ ), com dureza variando de 1051-1756 $\mathrm{HV}_{0,01}$ (média 1510 $\mathrm{HV}_{0,01}$ ), imersos em matriz eutética (austenita mais carbonetos) com dureza média de $668 \mathrm{HV}_{0,01}$.

A microestrutura do revestimento $\mathrm{FeCrC}+\mathrm{Nb}$ é apresentada na Figura 8, mostrando uma formação que se assemelha ao revestimento $\mathrm{FeCrC}$ (Figura 7a) para a região próxima ao metal de base (Figura 8a), ou seja, microestrutura com crescimento dendrítico na interface com o metal de base, menos evidente que o $\mathrm{FeCrC}$. A Figura $8 \mathrm{~b}$ mostra carbonetos primários $\left(\mathrm{M}_{7} \mathrm{C}_{3}\right)$, com dureza variando de 1168-1452 $\mathrm{HV}_{0,01}$ (média de $1356 \mathrm{HV}_{0,01}$ ), imersos em matriz com dureza média de $650 \mathrm{HV}_{0,01}$. Observase também a presença em todo o volume do revestimento (da interface do metal de base até a superfície) de pequenos carbonetos de nióbio $(5$ a $10 \mu \mathrm{m})$ finamente distribuídos na matriz. Esses carbonetos apresentam geometria diversa de forma similar ao obtido por Buchely et al. [8]. A sua dureza varia de 1027-1514 $\mathrm{HV}_{0,01}$ (média de $1207 \mathrm{HV}_{0,01}$ ), inferior ao obtido na literatura, em torno de $2400 \mathrm{HV}$ [8].

Hernandez [4] cita que as ligas do sistema $\mathrm{FeCrCNb}$ apresentam essencialmente o mesmo tipo de microestrutura das ligas contendo apenas $\mathrm{FeCrC}$, ou seja, dendritas de austenita com carbonetos $\mathrm{M}_{7} \mathrm{C}_{3}$ massivos, além da presença de carbonetos $\mathrm{NbC}$ na forma primária e secundária. Fato este também observado neste trabalho.

As Figuras 9a e 9b apresentam a microestrutura do revestimento $\mathrm{FeCrC}+\mathrm{Ti}$, onde observa-se em todo volume do depósito uma matriz bastante homogênea (parte escura), com dureza variando de 627 a $681 \mathrm{HV}_{0,01}$ (média de $654 \mathrm{HV}_{0,01}$ ) envolvendo carbonetos primários (carbonetos de titânio) de grandes dimensões, os quais podem variar de $25 \mu \mathrm{m}$, próximo à interface com o metal base, até mais de $150 \mu \mathrm{m}$ nas regiões próximas à superfície do cordão de solda. Os carbonetos de titânio, com dureza variando de 2050 a $2970 \mathrm{HV}_{0.01}$ (média de $2570 \mathrm{HV}_{0,01}$ ), apresentaram dureza inferior ao obtido por Berns 




Figura 7. Microestrutura da liga FeCrC.
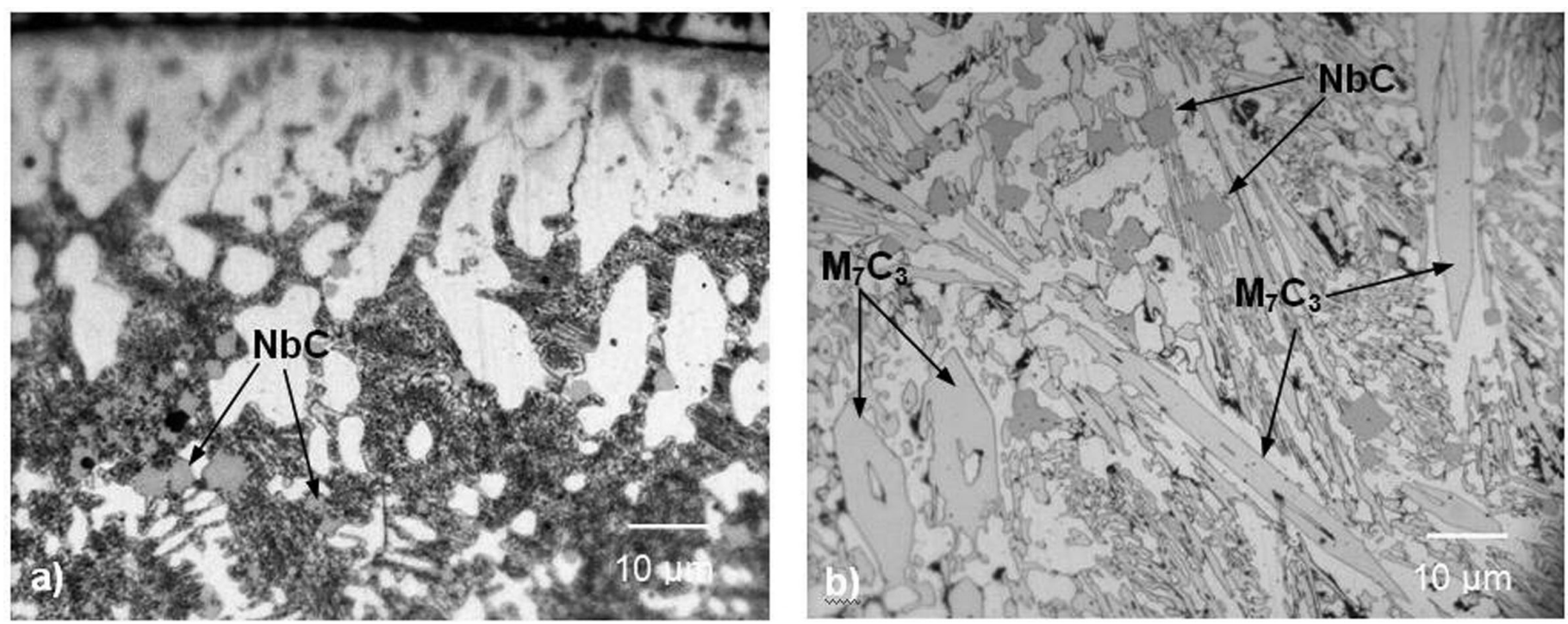

Figura 8. Microestrutura da liga $\mathrm{FeCrC}+\mathrm{Nb}$.
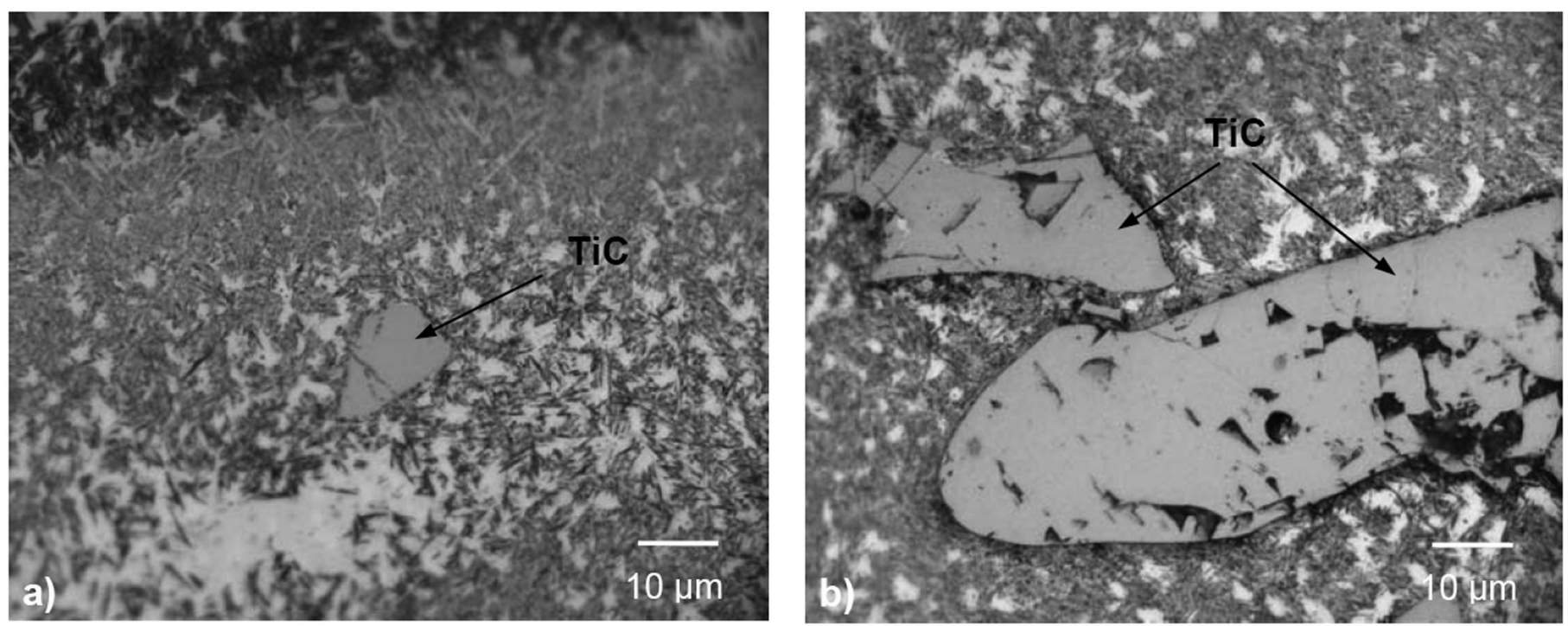

Figura 9. Microestrutura da liga $\mathrm{FeCrC}+\mathrm{Ti}$. 

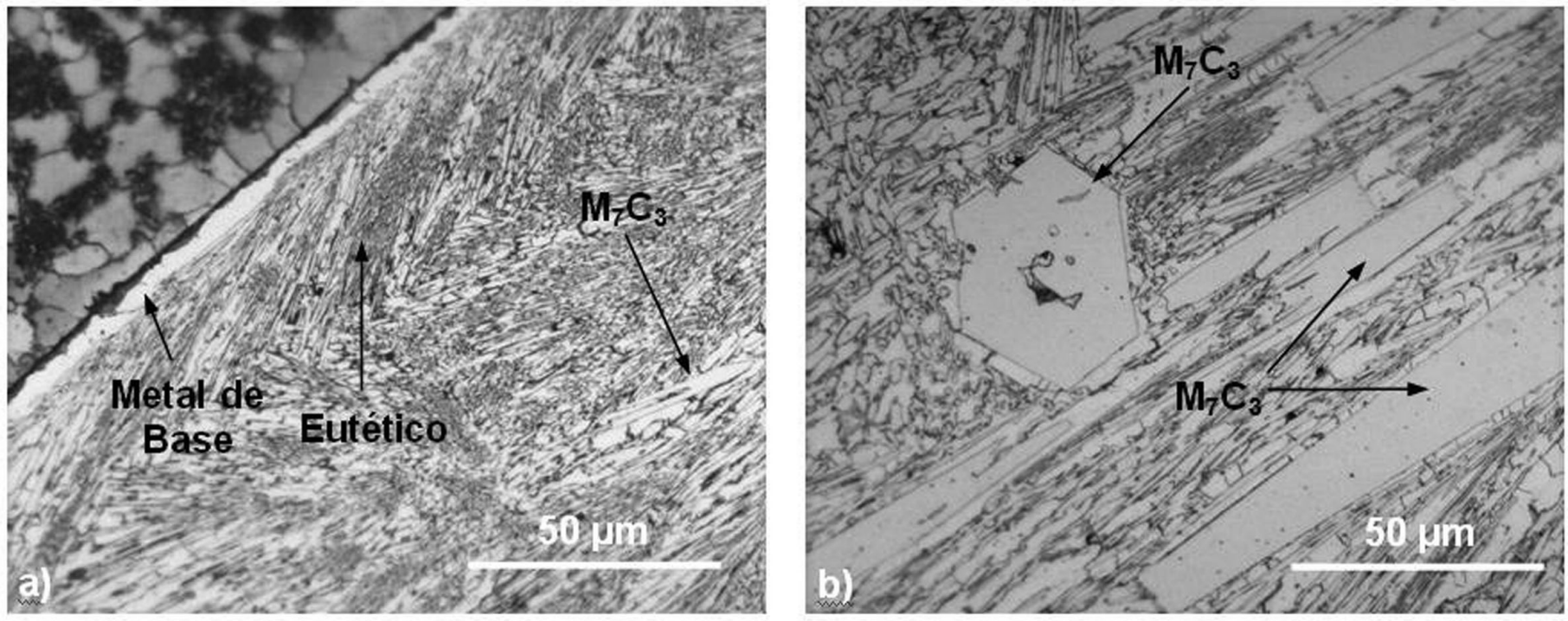

Figura 10. Microestrura do revestimento obtido com o eletrodo revestido ER1.

e Fisher [14], em torno de $3000 \mathrm{HV}_{0,01}$.

A Figura 10 apresenta a microestrutura do revestimento efetuado com o eletrodo ER1, onde se observa, na região da interface com o metal base, Fig. (10a), uma microestrutura predominantemente eutética, com uma distribuição de carbonetos do tipo $\mathrm{M}_{7} \mathrm{C}_{3}$ finamente dispersos na matriz. À medida que se aproxima do centro do revestimento, em direção à superfície, observa-se um aumento do tamanho dos carbonetos, com a presença de grandes e massivos carbonetos primários (Fig. (10b)), com dimensões que podem chegar a $50 \mu \mathrm{m}$ (diagonal do hexágono) por $200 \mu \mathrm{m}$ (comprimento) e dureza variando de 1050-1350 $\mathrm{HV}_{0,01}$. O tamanho desses carbonetos é superior ao observado no revestimento $\mathrm{FeCrC} \mathrm{e}+\mathrm{Nb}$, mas a sua dureza é inferior. A dureza da matriz varia de 498-782 $\mathrm{HV}_{0,01}$ (média de $\left.660 \mathrm{HV}_{0,01}\right)$. Em volta dos carbonetos massivos $\mathrm{M}_{7} \mathrm{C}_{3}$ observa-se ainda uma grande quantidade de carbonetos finos uniformemente distribuídos na matriz.

Segundo Polido e Gallego [15], os carbonetos massivos $(\mathrm{Fe}, \mathrm{Cr})_{7} \mathrm{C}_{3}$ ou $\mathrm{M}_{7} \mathrm{C}_{3}$ são os primeiros a se formarem na solidificação da poça de fusão rica em ferro, cromo e carbono. A região onde estão precipitados os carbonetos (matriz) é uma mistura de várias fases, composta principalmente de ferrita, carbonetos secundários do tipo $\mathrm{M}_{7} \mathrm{C}_{3}$ e carbonetos $\mathrm{M}_{23} \mathrm{C}_{6}$.

A porcentagem volumétrica de carbonetos totais ( $\mathrm{PVCt}$ ) foi obtida utilizando-se o software "Image Tools". O reagente Murakami $\left(60^{\circ} \mathrm{C}\right)$ ataca seletivamente os carbonetos, destacandoos da matriz e permitindo a sua seleção para a determinação da área superficial ocupada pelos mesmos, em comparação com $\mathrm{a}$ área total da figura. A Figura 11 apresenta a porcentagem volumétrica de carbonetos totais, obtida a partir da medição de três áreas com cada consumível. Observa-se dentre os arames tubulares, que a maior PVCt foi obtida com o $+\mathrm{Nb}$, seguido do $\mathrm{FeCrC}$ e do $+\mathrm{Ti}$, com resultados estatisticamente similares. $\mathrm{O}$ eletrodo revestido ER1 apresentou PVCt pouco inferior ao arame $+\mathrm{Nb}$, mas superior aos outros dois arames. Destacase que o grande desvio padrão do revestimento $+\mathrm{Ti}$ se deve à seleção de imagens com carbonetos finamente dispersos e outras com a presença de carbonetos grandes, os quais contribuem decisivamente para o aumento da PVCt.

Verifica-se que a PVCt é fortemente dependente da composição química dos consumíveis para os arames tubulares, sendo que o arame que tem maior porcentagem de elementos formadores de carbonetos, o $+\mathrm{Nb}$ (vide Tabela 1), também apresentou maior PVCt. Exceção se faz ao eletrodo ER1 que apesar do maior teor de cromo e carbono, apresentou PVCt inferior aos arames $\mathrm{FeCrC}$ e $+\mathrm{Nb}$, provavelmente devido à maior diluição da solda. (a soldagem foi realizada em condições diferentes dos arames tubulares).

Porcentagem Volumétrica de Carbonetos Totais

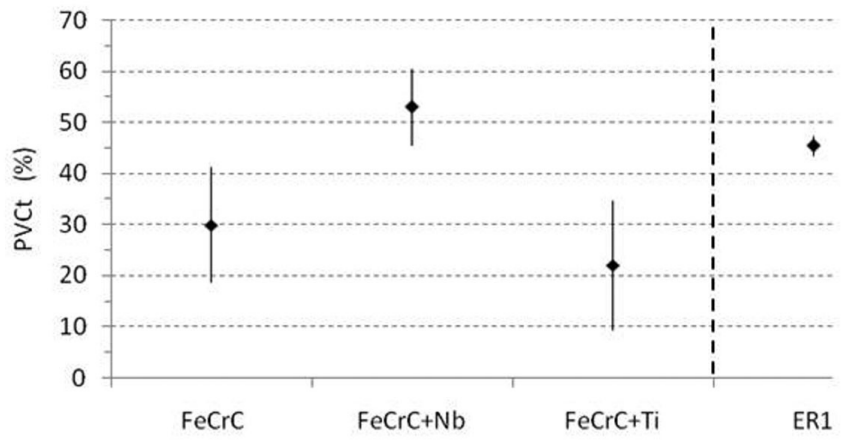

Figura 11. Porcentagem volumétrica de carbonetos totais.

O menor desempenho em termos de resistência ao desgaste da liga $\mathrm{FeCrC}$ se deve provavelmente à menor dureza do revestimento devido à sua microestrutura hipoeutética (dentritas de austenita em matriz eutética) de menores propriedades de resistência ao desgaste, concordando com Sevilla et al. [7], segundo os quais os revestimentos duros hipereutéticos ricos em cromo com carbonetos primários em matriz eutética apresentam melhor resistência ao desgaste abrasivo que aqueles compostos por constituintes eutéticos e austenita, este caso. Por outro lado, a maior resistência ao desgaste da liga $\mathrm{FeCrC}+\mathrm{Nb}$ está relacionada com a maior dureza do revestimento e à sua 
microestrutura hipereutética, formada por carbonetos primários de cromo $\left(\mathrm{M}_{7} \mathrm{C}_{3}\right)$ e monocarbonetos de nióbio $(\mathrm{NbC})$ em matriz eutética, sendo esses últimos finamente distribuídos, tendo inclusive a maior PVCt. Segundo Hutchings [16] e Corrêa et al. [17], conseguindo-se uma distribuição uniforme e pequeno espaço entre os carbonetos, as partículas abrasivas não podem efetivamente penetrar na matriz mais tenaz, levando a uma melhoria da resistência ao desgaste em combinação com uma maior tenacidade.

$\mathrm{O}$ desempenho da liga $\mathrm{FeCrC}+\mathrm{Ti}$, inferior ao $+\mathrm{Nb}$, se justifica pela presença de grandes carbonetos $\mathrm{TiC}$ intercalados por pequenos e duros carbonetos $\mathrm{TiC}$ fortemente incrustados e finamente distribuídos na matriz austenítica-martensítica e com menor valor de PVCt. Wang et al. [18] afirmam que os $\mathrm{TiC}$ apresentam maior dureza e estabilidade que os $\mathrm{CrC}$ e que materiais reforçados com TiC têm cadeias muito fortes, podendo exceder a $58 \mathrm{Mpa}$, além de elevada resistência ao desgaste. Entretanto, os massivos monocarbonetos TiC são frágeis e se fragmentavam sob a ação do abrasivo.

O eletrodo ER1 teve resistência ao desgaste pouco inferior ao arame $+\mathrm{Nb}$, pois, apesar da microestrutura formada por carbonetos de $\mathrm{Cr}$ primários em matriz eutética, os carbonetos $\mathrm{M}_{7} \mathrm{C}_{3}$ apresentaram tamanho superior ao da outra liga, além de porcentagem volumétrica inferior, o que segundo a literatura justifica o melhor desempenho do $+\mathrm{Nb}$ que apresentava ainda fina distribuição de carbonetos NbC. Atamert e Badeshia [19] afirmam que os carbonetos de cromo são duros e frágeis e, portanto, quando os carbonetos grandes são removidos da matriz durante o processo de desgaste, a perda de material da superfície se torna mais intensa. Por outro lado, tanto a microestrutura hipereutética do eletrodo revestido quanto à porcentagem volumétrica de carbonetos totais, superior aos outros dois arames lhe proporcionaram maior resistência ao desgaste que esses.

\section{Conclusões}

A análise dos resultados permite chegar às seguintes conclusões, dentre os arames tubulares:

$\checkmark$ A liga contendo $\mathrm{FeCrC}+\mathrm{Nb}$ apresentou maior resistência ao desgaste abrasivo de baixa tensão em depósitos em camada única que as ligas com a adição de $+\mathrm{Ti}$ e a liga $\mathrm{FeCrC}$;

$\checkmark \mathrm{O}$ arame $\mathrm{FeCrC}$ e o $+\mathrm{Nb}$ apresentaram trincas perpendiculares ao cordão, enquanto o arame $+\mathrm{Ti}$ não apresentou trincas visíveis;

$\checkmark$ Observou-se nas superfícies desgastadas a predominância de microcorte para todos os revestimentos utilizados. No arame $\mathrm{FeCrC}$ ficou mais evidente a predominância do microcorte com sulcos mais profundos. No revestimento $+\mathrm{Nb}$ observou-se, tanto microcorte, quanto microsulcamento. No revestimento +Ti observou-se um desgaste seletivo, isto é, regiões marcantes com diferentes resistências ao desgaste;

$\checkmark \mathrm{O}$ arame $\mathrm{FeCrC}$ proporcionou revestimentos com microestrutura formada por dendritas de austenita com eutética interdendrítica, a segunda maior porcentagem volumétrica de carbonetos totais (estatisticamente igual ao arame $+\mathrm{Ti}$ ), a menor dureza e resistência ao desgaste e, como conseqüência, a maior rugosidade superficial; $\checkmark \mathrm{O}$ arame $\mathrm{FeCrC}+\mathrm{Nb}$ proporcionou revestimentos com microestrutura formada por carbonetos de $\mathrm{Cr}$ primários $\mathrm{M}_{7} \mathrm{C}_{3} \mathrm{e}$ $\mathrm{NbC}$ em Matriz eutética, a maior porcentagem volumétrica de carbonetos totais, a maior dureza média do depósito e a maior resistência ao desgaste com menor rugosidade superficial da trilha de desgaste.

$\checkmark \mathrm{O}$ revestimento $+\mathrm{Ti}$ apresentou uma microestrutura formada por carbonetos $\mathrm{TiC}$ em matriz austenítica-martensítica, menor porcentagem volumétrica de carbonetos totais, dureza e resistência ao desgaste intermediárias, além de rugosidade superficial similar ao arame $\mathrm{FeCrC}$ e superior ao $+\mathrm{Nb}$

Em uma análise comparativa dos arames tubulares com o eletrodo revestido, mesmo em condições de soldagem diferentes, verifica-se que:

$\checkmark$ O eletrodo ER1 proporcionou revestimento com microestrutura formada por carbonetos de $\mathrm{Cr}$ primários $\mathrm{M}_{7} \mathrm{C}_{3}$ em matriz eutética, dureza e resistência ao desgaste, estatisticamente iguais ao arame $+\mathrm{Nb}$ (melhor desempenho), além de porcentagem volumétrica de carbonetos totais próxima desse arame.

\section{Agradecimentos}

Os autores expressam o seu agradecimento às instituições que apoiaram para realização deste trabalho (CNPq, CAPES, FAPEMIG, CEFET-GO e UFU).

\section{Referências Bibliográficas}

[1] JORNALCANA. Disponível em www.jornalcana.com.br. Acesso em: 25 de maio de 2008.

[2] SANTOS, A. S.; FRANCO. A. A.; ALMEIDA, D. M. e PERTICARRARI, M. Soldagem na Indústria Sucroalcooleira. Revista da Soldagem. Ano I, n. 7, p. 20-26, 2005.

[3] FIORE, N. F.; KOSEL, T. H. AND FULCHER, J. K. The Effect of Carbide Volume fraction on the Low Abrasion Resistance of High Cr-Mo White Cast Irons. Wear, n.84, p.313325, 1983.

[4] HERNÁNDEZ, O. J. S. Otimização do Consumível na Solda de Revestimento Aplicada na Indústria Sucroalcooleira. Universidade Federal de São Carlos. Dissertação de Mestrado. 1997, $102 \mathrm{p}$.

[5] MARTINS FILHO, A. S. Soldagem de Revestimentos com Arame Tubular. Universidade Federal de São Carlos. Dissertação de Mestrado. 1995, 93 p.

[6] PARANHOS, R. P. R.; MELLO, R. S. T.; PAYÃO FILHO, J. C. Influência dos Parâmetros de Soldagem com Arco Submerso Empregando Fluxo Ligado e Arame de Aço-C nas Características de Revestimento de Ligas Fe-Cr-C Resistentes ao Desgaste Abrasivo. XXIV Encontro Nacional de Tecnologia da Soldagem, XI Congresso Latino-Americano e V IberoAmericano de Soldagem. Fortaleza - CE, set. 1998.

[7] SEVILLA, L. M. L.; PINEDA, J. C. G. \& TORO, A. Relación Microestructura Resistencia al Desgaste de Recubrimientos Duros Ricos en Cromo y Tungsteno Aplicados por Soldadura Elétrica (SMAW). Dyna, año/vol. 71, n.144, p.165-171, 2004. [8] BUCHELY, M. F.; GUTIERREZ, J. C.; LEÓN, L. M. E.; 
TORO, A. The Effect of Microstructure on Abrasive Wear of Hardfacing Alloys. Tribology International. v.259, p.52-61, 2005.

[9] LIMA, A. C. E FERRARESI, V. A., Estudo dos Modos de Transferência Metálica de um Arame Tubular Autoprotegido com Variação da Distância Bico de Contato Peça. "Soldagem \& Inspeção", v.11, n.3, jul/set. 2006.

[10] ASTM. "Standard Test Method for Measuring Abrasion Using The Dry Sand/Rubber Wheel Aparatus". ASTM G65-91, p.231-243, 1991

[11] CARCELLER, R. C. Influencia de los Parâmetros del Régimen de Recargue en la Morfología de los Depósitos de Acero e Fundición Blanca al Cromo y su incremento en la Resistencia al Desgaste Abrasivo. Instituto Superior Politécnico José Antonio Echeverría, Facultad de Ingeniería Mecánica, República de Cuba, Tesis de Doctorado en Ciencias Técnicas, 154p. 2007.

[12] ZUM GHAR, K. H. Microstructure and Wear of Materials. Tribology Series, v. 10, Elsevier Science Publishers, Amsterdan. 560p. 1987.

[13] MUMMERY, L. Surface Texture Analysis: Thr Handbook. Hommelwerke GmbH, 106p. 1992.

[14] BERNS, H. AND FISCHER, A. Microstructure of Fe-Cr-C Hardfacing Alloys with Additions of $\mathrm{Nb}$, Ti and B. Materials Characterization, v.39. p.499-527, aug. 1997.

[15] POLIDO, R. S. E GALLEGO, J. Estudo da Microestrutura de Revestimento Duro Aplicado nos Equipamentos da Indústria Sucroalcooleira Sujeito ao Desgaste Abrasivo. Disponível em www.dem.feis.unesp.br/maprotec/ 2006/ Acesso em: 21 set. 2007.

[16] HUTCHINGS, I. M. Tribology: Friction and wear of engineering materials. CRC Press Inc., Boca Raton, USA, 273p. 1992.

[17] CORRÊA, E. O.; ALCÂNTARA, N. G.; TECCO, D. G.; KUMMAR, R. V. Avaliação de Resistência ao Desgaste de Ligas Fe-Cr-C-Nb-V Desenvolvidas para a Solda de Revestimento Duro para Uso sob Condições Altamente Abrasivas. " 8 vo Congreso Iberoamericano de Ingeniería Mecánica - CIBIM 8", Cusco, Peru, out. 2007.

[18] WANG, X. H.; ZOU, Z. D.; QU, S. Y. E SONG, S. L. Microstrutere and Wear propertiees of Fe-band Hardfacing Coating Reinforced by TiC Particles. Journal of materials processing Technology. P.3-6, nov. 2004.

[19] ATAMERT, S. AND BHADESHIA, H. K. D. H. Microstructure and Stability of Fe-Cr-C Hardfacing Alloys. “Materials Science and Engineering". n.130, p.101-111, 1988. 